\title{
ENHANCING POLLINATION SUPPLY IN AN URBAN ECOSYSTEM THROUGH LANDSCAPE MODIFICATIONS
}

Running head: Enhancing pollination in cities

Keywords: pollinator, bee, ecosystem service, lawn, landscape manipulation, spatial pattern, pollination service

Amélie Y. Davis ${ }^{1,2,3,{ }^{*}}$, Eric V. Lonsdorf ${ }^{4}$, Cliff R. Shierk ${ }^{5}$, Kevin C. Matteson ${ }^{6}$, John R. Taylor $^{7}$, Sarah T. Lovell ${ }^{8}$, Emily S. Minor ${ }^{3,5}$.

${ }^{1}$ Miami University, Department of Geography, 601 E. Spring Street, Oxford OH, 45056

${ }^{2}$ Miami University, Institute for the Environment and Sustainability, 601 E. Spring Street, Oxford $\mathrm{OH}, 45056$

${ }^{3}$ University of Illinois at Chicago, Institute for Environmental Science and Policy, 2121 West Taylor Street (MC 673), Chicago, IL 60612

${ }^{4}$ University of Minnesota, Institute on the environment,1954 Buford Ave, Saint Paul, MN 55108

${ }^{5}$ University of Illinois at Chicago, Biological Sciences, 845 W. Taylor Street (MC 066), Chicago IL 60607

${ }^{6}$ Miami University, Department of Biology, 13 Peabody Hall, Oxford OH 45056

${ }^{7}$ University of Rhode Island, Department of Plant Sciences and Entomology, 234 Woodward Hall, Kingston RI 02881

${ }^{8}$ University of Illinois at Urbana, Department of Crop Sciences, 1009 Plant Sciences Laboratory, 1201 S. Dorner Drive, Urbana IL 61801

* Corresponding author

Email: davis.amelie@miamioh.edu

Phone: 513.529 .0809 


\section{ABSTRACT}

2

3 Although urban agriculture is growing in popularity, little is known about the distribution of

4 insect pollinators across urbanized landscapes. We used the pollination module of InVEST (a

5 suite of software models used to map and value ecosystem services), along with fine-scale land

6 cover data and empirical data on bee distributions, to assess different scenarios of urban

7 pollinator management in Chicago, Illinois (USA). Specifically, we simulated the partial

8 conversion of lawn/turf-grass to floral resources in city parks only, in gardens managed by

9 individual households only, and in any available turf grass within buffer distances of 250 to 1000

$10 \mathrm{~m}$ of urban farms, community gardens, and home gardens across Chicago. We found that the

11 output of InVEST's pollination model was significantly related to empirical measures of bee

12 richness (explaining $46 \%$ of the variation) but not bee abundance in Chicago. To increase

13 pollination supply at urban farms and community gardens, our results indicate that, out of the

14 scenarios presented here, the best strategy for the City of Chicago would be to concentrate floral

15 resources nearby (within a $250 \mathrm{~m}$ buffer rather than within a $1 \mathrm{~km}$ buffer). In contrast, for home

16 gardens, the model indicates that it may be better to increase floral resources throughout the city.

17 This discrepancy may be due to the smaller size of home gardens and their more dispersed

18 spatial arrangement throughout the city. Generally, our results indicate that converting turf grass

19 to a more florally-rich land cover would support increased supply of pollinators and urban

20 agriculture. 


\section{INTRODUCTION}

In recent years, interest in residential food gardens, community gardens, and urban farms,

23 aka urban agriculture, has been growing (Tornaghi, 2014). The crops grown in these gardens may increase urban sustainability and food security (Colasanti et al., 2012). However, many

25 urban crops, such as cucumbers and squash, depend on pollination services provided by insects

26 (Matteson \& Langellotto, 2009), and several studies have shown not only a decrease in pollinator

27 diversity with urbanization or human population density (Ahrné et al., 2009, Bates et al., 2011,

28 Matteson et al., 2013) but also a shift in species composition (Banaszak-Cibicka \& Zmihorski,

29 2012; Cane et al., 2006). Other research suggests that pollination services and seed set may be

30 limited (Leong et al., 2014; Pellissier et al., 2012) or variable (Lowenstein et al., 2015) in urban

31 areas, possibly due to the distribution of floral resources or to low pollinator abundance. Efforts

32 to conserve urban pollinators could also boost productivity of urban agriculture.

Wild insects can be highly effective pollinators of agricultural crops (Garibaldi et al.,

2013). Studies from rural systems indicate that high quality habitat in the surrounding landscape

35 benefits the wild pollinator community (Kennedy et al., 2013; Ricketts et al., 2008). Nearby

floral resources and nesting sites have been linked to increased pollinator diversity (Potts et al.,

37 2003; Potts et al., 2005) and pollination services (Blanche et al., 2006; Holzschuh et al., 2012).

38 In urban areas, wild bees are often more abundant than honey bees (Leong et al., 2014;

39 Lowenstein et al., 2015), but high quality bee habitat may be scarce or distributed in ways that

40 do not benefit urban agriculture. For instance, Matteson and Langellotto (2010) found that only

$41 \quad 10-32 \%$ of the landscape surrounding urban gardens in New York City had vegetation of any

42 type, with most of this being sparsely distributed street-trees, heavily-managed gardens, or urban

43 parks. However, bee diversity in heavily developed landscapes may be maintained to some 
44 degree by ornamental flowers in urban gardens and other managed habitats (Fetridge et al., 2008;

45 Frankie et al., 2005; Lowenstein et al., 2014; Matteson \& Langellotto, 2011). Increasing floral

46 resources may provide an important mechanism for counteracting the negative impacts of urban

47 development on pollinators. One common land cover which could be potentially modified to

48 provide increased floral resources is turf grass or lawns.

Turf grass is a common land cover in residential, commercial, industrial, and recreational

50 areas in U.S. cities. Turf grasses cover approximately $163,800 \mathrm{~km}^{2}\left(+/-35,850 \mathrm{~km}^{2}\right)$ of the

51 conterminous U.S., an area three times larger than that of any irrigated crop (Milesi et al., 2005).

52 In Franklin County, Ohio (USA), residential lawns were estimated to cover $23 \%$ of the county

53 (Robbins \& Birkenholtz, 2003). If a small amount of turf grass was modified or converted to

54 floral resources, the benefits to urban bees and pollination services could be substantial

55 (Blackmore \& Goulson, 2014).

Using information on pollinator nesting resources and floral resources, Lonsdorf et al.

57 (2009) predicted the relative abundance of pollinators available to pollinate farm crops. This

58 approach, based on the suite of software models used to map and value ecosystem services called

InVEST (Sharp et al., 2014), has not been tested in urban systems. However, it could potentially

60

61

62

63

64

65

66 provide a useful approach for evaluating scenarios and developing land-use plans that promote and improve urban agriculture. We used InVEST to examine the potential for converted urban lawns to enhance pollination supply in Chicago, Illinois (USA). We first tested whether the InVEST pollination model (Sharp et al. 2014) can predict pollinator abundance and richness in urban areas and validated the spatially explicit model output against empirical field data. We then modeled the supply of pollination provided to approximately 4000 urban farms, community gardens, and home food gardens within the city limits. With different scenarios and spatial 
67 configurations, we converted areas of turf grass to flower gardens and evaluated the effect on

68 pollination supply. The scenarios mimic three different management approaches by which to

69 increase floral resources in the city. The first scenario mimics a city-led effort which focuses on

70 city parks, the second scenario targets private yards managed by individual households, and the

71 third is a combination of the first two but is a scale-dependent assessment. These scenarios were

72 intended to evaluate the success of various strategies for enhancing urban pollination supply in

73 Chicago, Illinois, USA.

74

75 2. METHODS

76

77

78

79

80

81

82

83

84

85

\subsection{Study area}

Chicago, Illinois is the third largest city in the United States, with just over 2.5 million residents (2010 U.S. Census). Approximately $21.3 \%\left(126 \mathrm{~km}^{2}\right)$ of the city is covered by turf grass (Figure 1). Turf grass in this study refers to intensely managed grass that is treated with insecticides and herbicides and mowed frequently (e.g., most golf courses) as well as lawns that contain lawn weeds such as dandelions (Taraxacum officinale) and white clover (Triofolium repens) which provide floral resources for pollinators in urban areas (Larson et al. 2014). Common lawn species in this area include Kentucky bluegrass (Poa pratensis), perennial ryegrass (Lolium perenne), and fine and tall fescues (multiple species including Schedonorus arundinaceus), although these vary depending on specific management.

We used the location of urban farms, community gardens, and home food gardens as identified from Google Earth imagery by Taylor and Lovell (2012). In their study, Taylor and Lovell differentiated between various types of urban agriculture, e.g., urban farms, community 
gardens, and home gardens, among others. An urban farm was defined as a "large garden

90

91

92 comprising more than one vacant lot, with no apparent internal divisions except those created by crops, suggesting unified management by a single gardener/farmer or group"; while a community garden was defined as "a garden apparently divided into individual plots" (Taylor \& Lovell, 2012). In the present study, we consider community gardens and urban farms as one type of urban agriculture (larger in extent), as opposed to residential food gardens which are smaller and managed by individual households. The distribution of these two garden types (community/urban gardens versus residential gardens) across Chicago can be seen in Figure 1.

We assumed that these various types of urban agriculture grow similar crops and thus would have similar per area pollination requirements, and that they did not keep honey bee (Apis mellifera) hives on the premises.

\subsection{Field work for model validation}

Pollinator specimens were collected at 15 community gardens across Chicago (Figure 2). The sites were chosen opportunistically, based on the garden manager's interest in the project, accessibility of the garden, and presence of an open area to set up the sampling grid. We have no reason to think that the gardens we studied were significantly different from other gardens in terms of floral resources or pollinators. We collected pollinators at each garden using pan traps (4 oz. soufflé cups painted white, yellow, or blue and filled with a detergent solution) placed on the ground in a $3 \mathrm{~m} \times 3 \mathrm{~m}$ grid, with all pan traps one meter apart and not immediately adjacent to a pan trap of the same color. The grid placement was based on the available space in the garden and located away from footpaths when possible. Floral resources were not measured at the gardens. One of the sites bordered a golf course and the bee bowls were placed near tree 
111 canopy. Very low bee abundance and richness were observed at this site and it was removed

112 from subsequent modeling $(\mathrm{n}=14)$.

113 Collections were performed once per month during July, August, September, and October

114 of 2009, and each collection was performed at all sites within a three-day span. The grid of pan

115 traps was left out for one daylight cycle on a sunny, calm day, either being set up and collected

116 within the same day (set up in the morning, collected in the evening) or left out for a 24-hour

117 period. This method is adapted from the bee monitoring protocol outlined in Droege (2012).

After the collection period, the contents of all pan traps were strained, placed in a

119 watertight bag, and preserved with 95\% ethanol. The specimens were later pinned, labeled, and

120 sent out for identification by two recognized experts (John Ascher and Sam Droege). Specimens

121 in the Apoidea superfamily were identified to species level, and all other Hymenoptera

122 specimens were identified to genus. We measured distance between wing bases (intertegular

123 span) for all specimens, using methods adapted from Greenleaf et al. (2007). For small

124 specimens, we used a measuring reticule in the ocular of microscope. For large specimens, we

125 used a finely graduated $(0.1 \mathrm{~mm})$ ruler. All measurements were rounded to the nearest $0.1 \mathrm{~mm}$.

126

127

128

129

130

131

132

\subsection{Modeling pollination supply}

Pollination supply was modeled across the landscape in a spatially explicit manner using the crop pollination module of InVEST 2.1 in ArcGIS 10.0 (ESRI). The mathematical model underlying the InVEST pollination model is described in Lonsdorf et al. (2009). The model uses expert estimates about nesting and floral resources across the landscape to create a map of source habitat for pollinators. Based on the distribution of source habitat and the foraging range of pollinators, the model then calculates a relative index of bee abundance for each location (here, a 
133 pixel) in the landscape. This spatially explicit map can be thought of as an index of pollination 134 supply.

Model inputs include a land cover map, information about nesting and floral resources in each land cover type, and information about the pollinators in the area. We used a land cover

137 dataset derived from Quickbird satellite imagery (4 spectral bands, $0.6 \mathrm{~m}$ spatial resolution) 138 acquired during the summers of 2007 and 2008. The images were orthorectified and classified 139 using automated feature extraction to obtain 7 original land cover classes, which were aggregated 140 into 5 classes: impervious surface, water, bare soil, trees, and grass (Table 1). The 'grass' class 141 contains heavily managed turf grass (such as on golf courses), weedy turf grass that might 142 include clover or other small, herbaceous flowering plants, and land covered in forbs. Only the 143 latter two vegetation types would be expected to provide floral resources. Our original land cover 144 data did not include a separate class for flower beds, which were lumped into the 'grass' 145 category, i.e. the grass land cover can really be thought of as any non-woody vegetated land 146 cover. Due to computational limitations, we resampled the original data to 5 meter spatial 147 resolution using ArcGIS 10.0 (ESRI). The class that had the most coverage within the $5 \mathrm{~m}$ by 5 148 m pixel was assigned as the new land cover class for that pixel. The model can be adjusted by season and region. In Lonsdorf et al. (2009), the model 150 was tested using bee data from coffee farms in Costa Rica, as well as in semi-agricultural 151 systems in New Jersey, Pennsylvania, and California. In that study, the authors modeled between 152 two and four nesting guilds as well as three flight seasons (spring, summer and autumn). 153 Additionally, the model has been validated with field data from 39 different studies across a 154 range of biomes including tropical and subtropical, Mediterranean, and other temperate biomes 
155 (Kennedy et al., 2013). The regional adjustments are made by changing the floral and nesting 156 resource scores for the region of interest before running the model.

We assigned a value for pollinator nesting and floral resources to each land cover class

(Table 1) based on Kennedy et al.'s (2013) work synthesizing floral resource values for

159 standardized land cover types across 39 studies. Water and impervious surfaces (e.g. asphalt, rooftops) cannot provide nesting or floral resources for wild bees and therefore were assigned a

161 score of zero. Bare soil does not contain any flowers (and consequently was assigned a score of 162 zero for floral resources) but can provide nesting resources for ground nesting bees in particular.

163 Bare soil pixels were thus assigned a score of 0.25 as a nesting substrate to match those reported

164 in Kennedy et al. (2013, see Table S4). The grass class was assigned a nesting score of 0.5

165 because we combined the nesting scores for Grassland/Herbaceous score (0.64) and

166 Pasture/fallow fields (0.36) from Kennedy et al. (2013). The floral resource index for 'grass' was

167 set to 0.3 on a possible scale from zero to one, with zero being a land cover that provides no

168 floral resources for bees (Table 1). This essentially means that in one $25 \mathrm{~m}^{2}$ pixel of grass, $30 \%$

169 of the land would contain floral resources that are beneficial to bees during the months that bees

170 are active. This corresponds to our personal observations of lawns and gardens in the region

171 while doing field work for another study (Minor et al., 2016).

Other model inputs include information about the various bee guilds or species present in

173 the area, such as their nesting substrates, preferred foraging season(s), and foraging range. For

174 this study, we modeled a single representative, i.e. generic, pollinator species that characterizes

175 all wild bee species in the area. The foraging range for this representative bee was calculated as

$176700 \mathrm{~m}$, based on the mean intertegular span (Greenleaf et al., 2007) of all the bee genera caught

177 during field work (Table A1). The representative bee could nest both in the ground and in 
178 cavities. We also considered just one foraging season which represents the general quality of

179 forage across seasons, i.e. while bees are active in the Chicago region.

180

181

182

183

184

185

186

187

188

189

190

191

192

193

194

195

196

197

198

\subsection{Scenarios modifying floral resources}

We increased floral resources in grassy areas to simulate scenarios of various stakeholders replacing existing grass cover with flowering plants that would be beneficial to pollinators. In Scenario 1, pixels in city parks that were classified as grass were converted to flower gardens. The flower garden would theoretically include multiple species of flowers that are attractive to pollinators and that (in combination) bloom throughout the bees' active season.

This scenario simulates the decision by park managers to increase floral resources in their parks. In scenario 2, grass was converted to flower gardens only in residential (i.e. home) gardens; this simulates individual residents' decision to plant more pollinator-beneficial flowers in their yards. In scenario 3, existing grass was converted to flower gardens only if it was located within $250 \mathrm{~m}$, $500 \mathrm{~m}, 750 \mathrm{~m}$, or $1000 \mathrm{~m}$ of the community gardens identified by Taylor and Lovell (2012) and pictured in Figure 1. Scenario 3 thus consisted of 4 sub-scenarios where we varied the distance within which we concentrated the added floral resources. Any grass (whether in public parks or yards managed by individual households) was available for conversion in scenario 3 . This last scenario simulates a situation where planting floral resources might be incentivized for residents who live around existing urban farms and community gardens and would also be increased in nearby public parks. This scenario might simulate urban farmers working with the neighboring community to enhance floral resources that are beneficial for pollinators. These scenarios are summarized in Table 2. 
For each scenario, two levels of modification were modeled. The first level converted $2001 \%$ of all grass in the city to flower gardens. The second level converted $5 \%$ of all grass in the 201 city to flower gardens. A five percent conversion was considered the maximum possible because, 202 in the parks scenario, it would leave half of the grass acreage in parks for recreation. Given that 203 Chicago parks are heavily used for activities such as soccer, baseball, and picnics, we felt it was 204 necessary to leave a substantial portion of turf grass for such activities. For all scenarios, the 205 percentage of grass pixels converted to flower gardens was calculated across the entire city, not 206 per individual park or yard, and converted pixels were allocated randomly to existing grass 207 pixels in the landscape (within the boundary conditions described above). For scenarios 2 and 3 , 208 randomly converting grass pixels to flower gardens is a reasonably realistic scenario, as a $5 \mathrm{~m} \mathrm{x}$ $2095 \mathrm{~m}$ pixel is roughly the size of a residential garden in our study area. The random allocation of 210 these floral enhancements was done 20 times for each scenario (10 times for level 1 and 10 times

211 for level 2) for a total of 120 output maps. We examined the impact of each scenario on 212 pollination supply in residential gardens and community gardens separately.

\section{RESULTS}

\subsection{Local Bee Community and Model fit}

We collected 433 individual bees, representing 14 genera (Table A1). The greatest

217 abundance of bees was observed in the following genera: Lasioglossum, Agapostemon, and 218 Halictus. The model predicted $21 \%$ of the variance in observed bee abundance $(\mathrm{p}=0.098, \mathrm{n}=$ 21914 , Figure $3 a)$ and $46 \%$ of the native bee richness $(p=0.008, n=14$, Figure $3 b)$. The spatially 220 explicit map of the supply of pollination suggests that some areas of the city are likely to receive 
221 much more pollination than others (Figure 2). Chicago's urban parks and forest preserves are

222 seemingly 'pollination supply hotspots', as are the marshy areas on the south side of Chicago.

223 Areas where pollination supply might be deficient are located around the south branch of the

224 Chicago River, which is heavily industrialized, and the downtown area. In general, the index of

225 pollinator supply increased with distance from downtown, which would indicate greater bee

226 abundance and richness on the outskirts of the city.

2273.2 Scenarios

228

229

230

231

232

233

234

235

236

237

238

239

240

241

242

In all cases, when only converting $1 \%$ of the city's grass to pollinator friendly flower gardens, there were no statistically significant differences in pollination supply scores between the baseline data and any scenario means as determined by one-way $\operatorname{ANOVA}(\mathrm{F}(6,1682)=$ 0.262, $\mathrm{p}=0.95$, for urban farms and community gardens, and $\mathrm{F}(6,14700)=0.202, \mathrm{p}=0.98$, for residential gardens). Indeed, pollination supply score increases compared to the baseline were negligible in all the scenarios (Figure $4 \mathrm{a}$ and $\mathrm{b}$; note that the range of the y-axes vary).

When converting $5 \%$ of grass in the study area to pollinator friendly flower gardens, oneway ANOVAs revealed statistically significant differences in pollination supply scores between scenario means for the urban farms and community gardens $(F(6,1700)=5.72, p<0.001)$ as well as for the residential gardens $(F(6,14700)=4.08, \mathrm{p}<0.001)$. Post hoc comparisons using the Tukey HSD test indicated that, for the urban farms and community gardens (Figure 5a), two scenarios differed from the baseline scenario $(\bar{x}=0.022$, sd $=0.014)$ : floral enhancements within $250 \mathrm{~m}(\bar{x}=0.030, \mathrm{sd}=0.019)$ and within $500 \mathrm{~m}(\bar{x}=0.026, \mathrm{sd}=0.017)$ from the urban farms (Figure 4c, see lines that are starred in Figure 5a). Floral enhancements within $250 \mathrm{~m}$ of a farm resulted in significantly higher pollination supply scores than enhancements within $750 \mathrm{~m}$ 
243 of farms $(\bar{x}=0.025$, sd $=0.016)$, within $1 \mathrm{~km}$ of farms $(\bar{x}=0.024$, sd $=0.016)$, in parks $(\bar{x}=$

$2440.025, \mathrm{sd}=0.020)$, and in yards $(\bar{x}=0.023, \mathrm{sd}=0.015$, Figure 5a). No other comparisons were

245 significantly different. In contrast, for pollination supply scores in residential/home food gardens

246 (Figure 5b), enhancing floral resources in yards $(\bar{x}=0.021, \mathrm{sd}=0.013)$ or within $1 \mathrm{~km}$ of urban

247 farms $(\bar{x}=0.020, \mathrm{sd}=0.013)$ are the only scenarios that differed significantly from baseline

248 (Figure 4d, see lines that are starred in Figure 5b). In all cases, the parks scenario has the most

249 spatial variability due to some community gardens or residential gardens being fortuitously close

250 to the parks where we increased floral resources (Figure 4).

\section{DISCUSSION}

The goals of this study were to test the ability of the InVEST's pollination model to

254 predict pollinator abundance and richness in urban areas and to model various strategies for 255 improving pollination supply for urban agriculture. While the model output was not significantly

256 related to our empirical measures of bee abundance, it was significantly related to bee richness.

257 As bee richness has been shown to be a predictor of pollination services (Lowenstein et al., 258 2015), InVEST's pollination model could help cities identify where pollination supplies are 259 lacking and thus help them a) determine where efforts are needed to correct the deficiency and b) 260 establish a plan to involve citizens and gardens, park, and open space managers to plant 261 pollinator friendly plants in the green spaces they manage.

263 increasing the supply of pollinators in Chicago will depend on whether the main focus is on 264 home food gardens or on community gardens and urban farms. If the objective is to enhance 
265 pollination supply for home gardeners, then converting turf grass in people's yards to flower 266 gardens or within $1 \mathrm{~km}$ of urban farms and community gardens would be beneficial. However,

267 to enhance pollination at existing urban farms and community gardens in Chicago, the best

268 strategy is to concentrate the increased floral resources close to the farms themselves. Since

269 Taylor and Lovell (2012) found that community gardens and urban farms make up 25.3\% of the

270 area devoted to urban agriculture in Chicago, while residential gardens make up 45.1\% (the rest

271 being mostly cultivated in school gardens (1.1\%) as well as vacant lots (27.2\%)), increasing

272 pollination supply for residents city wide instead of for urban farms and community gardens

273 could arguably be more important if residential gardens are as productive as urban farms and

274 community gardens on a per area basis.

To increase the number of bees visiting urban agriculture sites in Chicago, it is clear that

276 concentrating floral resources around where the crops are being grown is the best option.

277 Indeed, the two scenarios that concentrate the floral resources the most (i.e. in parks and in a 250

$278 \mathrm{~m}$ radius from farms) are the ones with the largest increase in pollination supply score. These

279 modeling results confirm recommendations from the literature; Brosi et al. (2008) suggest that to

280 ensure sufficient levels of pollination (in an agricultural landscape) it is best to conserve bee

281 habitat in small parcels throughout the landscape where pollination is needed. While some

282 evidence suggests that urban farmers and community gardeners do modify the property's

283 resources (i.e. the same parcel they are gardening) to attract bees (Pawelek et al., 2009), the

284 extent to which this strategy is used by urban "farmers" (both in home gardens and in community

285 gardens) is unknown and would warrant further research. It is also interesting to note, that while

286 there is increased interest in maintaining honey bee (Apis mellifera) hives in some cities,

287 Lowenstein et al. (2015) found that the majority of pollinators visiting sentinel plants in an urban 
288

289

290

291

292

293

294

295

296

297

298

299

300

301

environment were wild, native bees. To our knowledge, none of the crops grown in Chicago rely exclusively on honey bees for pollination. Increasing floral resources could help promote a diversity of bees, thus decreasing reliance on a single species.

Additionally, the results of this modeling exercise should be independently verified via landscape manipulation experiments and field observations. Augmenting floral resources in different spatial arrangements throughout the city and measuring the effect not just on pollinator abundance and richness but also on seed set of pollinator-dependent plants would be informative. Blackmore and Goulson (2014) conducted a similar experiment (non-randomized) in an urban area in the United Kingdom (UK) and found that planting wildflower areas in what was previously turf grass significantly increased pollinator abundance, but they did not look at seed set or test various spatial arrangements of the experimental increase in floral resources. An interesting scenario might be to cluster some of the newly-created flower gardens, rather than randomly allocating them, simulating park managers aggregating gardens for efficiency or neighbors influencing each other's gardening choices.

Changing the norms of what people consider an acceptable yard is difficult (Robbins, 2012). Gobster (1999) states the importance of the public's familiarity with plants that researchers want people to adopt. This might be achieved through educational campaigns and demonstration sites. We surmise that using similar strategies to prompt individuals to provide resources for pollinators could be successful. Research in the UK has indicated that the general public does support providing habitat for insects in public parks, and a majority of park visitors reported that their enjoyment of the park had either stayed the same or increased after half of the grass area in a 6 ha park was replaced with wildflowers (Garbuzov et al., 2015). Similar studies in the U.S. are needed. 


\subsection{Limitations}

Our land cover layer only had five land cover classes and greatly simplified the Chicago

313 landscape. More land cover classes, especially for the non-built environment (such as

314 differentiating managed grass from herbaceous plants) would most likely improve the modeling

315 efforts, as would taking into consideration habitat patch size and dynamics of bee populations

316 over time.

Similarly, the spatial resolution $\left(25 \mathrm{~m}^{2}\right.$ pixels $)$ may be too coarse to detect the fine-scale

318 variability in people's yards. Minor et al. (2016) surveyed 600+ yards in Chicago and showed

319 that the structure of yards is complex and that most people (78\%) had at least one flowering plant

320 in their yard, i.e. the majority of people do not solely have turf grass or trees in their yard. While

321 we attempted to account for this by assuming that $30 \%$ of the land classified as grass contains

322 floral resources, finding many households that would be willing to convert a part of their lawn to

323 a flower garden may be unrealistic, especially for families with children or dogs. On the other

324 hand, just reducing the frequency of the mowing regimen of turf grass areas may be beneficial

325 for pollinators (Garbuzoz et al., 2015; Smith et al., 2015). Whether or not those changes would

326 be more or less acceptable to homeowners compared to converting lawn area to flower beds, and

327 how mowing affects bees in particular, need to be further investigated. Indeed, there may be

328 several barriers to modifying people's yards, as grassy areas are well suited for recreation, and

329 the planting and maintenance of flowering plants is more time consuming (and may require more

330 knowledge) than simply mowing turf grass.

Our study only considered bees and did not examine other pollinators, although bees are

332 generally considered to be the most important pollinators in eastern North America and they also 
333 are the most abundant pollinators in the city of Chicago (Lowenstein et al., 2015). However, it is

334 important to note that the presence of bees in a location does not always translate to greater seed 335 set (Leong et al., 2014) and that enhancing crop pollination services is only part of the solution 336 to conserve pollinator diversity (Senapathi et al., 2015), so caution should always be used when 337 interpreting results of models such as InVEST's pollination model.

Lastly, few validation sites were located in the more economically disadvantaged areas of 339 south and west Chicago. Given the many lines of evidence for increased floral diversity with 340 increasing income (Hope et al., 2003), the model, as we implemented it here, does not integrate 341 this potentially important subtlety of yard management.

\subsection{Future research}

Floral resources are not the only limitation bees face in urban or agricultural

344 environments; nesting resources may be limiting as well. Running similar scenarios while 345 modifying nesting resources (such as bare ground, or stems of trees and bushes; Potts et al., 346 2005) could provide further insight into how to enhance pollination supply in an urbanized area.

347 Similarly, given that urban plant communities are novel assemblages that affect the temporal 348 dynamics of pollinators (Leong et al., 2016), an interesting follow up to this study would be to 349 model seasonality as well. These types of analyses could also be conducted for the other 350 ecosystem services that can be modeled with InVEST, such as carbon sequestration. This 351 approach would enable the identification of tradeoffs and synergies between different ecosystem

352 services in urban areas. Lastly, while we do not expect that different residents would 353 intentionally aggregate their gardens to facilitate management, park managers (e.g. scenario 1) 354 might want to aggregate these areas of converted lawns within each park, in which case random 
355 conversion of grass to flower gardens might not be completely realistic. Future work could 356 examine the impact of different spatial patterns of lawn conversion.

\section{CONCLUSIONS}

359 Pollination supply varies greatly across Chicago and the benefits provided by Chicago's large 360 urban parks, green boulevards, and forest preserves should not be understated. We found that 361 augmenting floral resources in an urbanized environment such as Chicago can improve the 362 supply of pollinators, but that those efforts should be concentrated around areas where 363 pollinators are especially needed, such as urban farms and community gardens. More research is 364 needed to determine how many bee species or what bee abundance is "sufficient" for private 365 gardens and urban farms in highly urbanized environments. 


\section{REFERENCES}

Ahrne, K., Bengtsson, J., \& Elmqvist, T. (2009). Bumble bees (Bombus spp) along a gradient of increasing urbanization. PLOS ONE, 4(5), e5574.

Banaszak-Cibicka, W. \& Żmihorski, M. (2012). Wild bees along an urban gradient: winners and losers. Journal of Insect Conservation, 16, 331-343.

Bates, A.J., Sadler, J.P., Fairbrass, A.J., Falk, S.J., Hale, J.D., \& Matthews, T.J. (2011). Changing bee and hoverfly pollinator assemblages along an urban-rural gradient. PLOS ONE, 8:e23459.

Blackmore, L. M., \& Goulson, D. (2014). Evaluating the effectiveness of wildflower seed mixes for boosting floral diversity and bumblebee and hoverfly abundance in urban areas. Insect Conservation and Diversity, 7(5), 480-484.

Blanche, K., Ludwig J., \& Cunningham S. (2006). Proximity to rainforest enhances pollination and fruit set in orchards. Journal Of Applied Ecology, 43:1182-1187.

Brosi, B. J., Armsworth, P. R., \& Daily, G. C. (2008). Optimal design of agricultural landscapes for pollination services. Conservation Letters, 1(1), 27-36.

Cane, J. H., Minckley, R. L., Kervin, L. J., Roulston, T. H. \& Williams, N. M. (2006). Complex Responses Within A Desert Bee Guild (Hymenoptera: Apiformes) To Urban Habitat Fragmentation. Ecological Applications, 16, 632-644.

Colasanti K.J.A., Hamm M.W. \& Litjens C.M. (2012). The City as an "Agricultural Powerhouse"? Perspectives on Expanding Urban Agriculture from Detroit, Michigan. Urban Geography, 33(3), 348-369.

Droege, S. (2012). The Very Handy Manual (retrieved from: http://www.pwrc.usgs.gov/nativebees/Handy\%20Bee\%20Manual/Handy\%20Bee\%20Manual.pd f)

Fetridge, E. D., Ascher, J. S., \& Langellotto, G. A. (2008). The bee fauna of residential gardens in a suburb of New York City (Hymenoptera: Apoidea). Annals of the entomological Society of America, 101(6), 1067-1077.

Frankie, G. W., Thorp, R. W., Schindler, M., Hernandez, J., Ertter, B., \& Rizzardi, M. (2005). Ecological patterns of bees and their host ornamental flowers in two northern California cities. Journal of the Kansas Entomological Society, 78(3), 227-246.

Garbuzov, M., Fensome, K. A., \& Ratnieks, F. L. (2015). Public approval plus more wildlife: twin benefits of reduced mowing of amenity grass in a suburban public park in Saltdean, UK. Insect Conservation and Diversity, 8(2), 107-119. 
Garibaldi, L. A., Steffan-Dewenter, I., Winfree, R., Aizen, M. A., Bommarco, R., Cunningham, S. A., ... \& Bartomeus, I. (2013). Wild pollinators enhance fruit set of crops regardless of honey bee abundance. Science, 339(6127), 1608-1611.

Gobster, P. H. (1999). An ecological aesthetic for forest landscape management. Landscape journal, 18(1), 54-64.

Greenleaf, S. S., Williams, N. M., Winfree, R., \& Kremen, C. (2007). Bee foraging ranges and their relationship to body size. Oecologia, 153(3), 589-596.

Holzschuh, A., Dudenhöffer, J., \& Tscharntke, T. (2012). Landscapes with wild bee habitats enhance pollination, fruit set and yield of sweet cherry. Biological Conservation, 153:101-107.

Hope, D., Gries, C., Zhu, W., Fagan, W. F., Redman, C. L., Grimm, N. B., ... \& Kinzig, A. (2003). Socioeconomics drive urban plant diversity. Proceedings of the National Academy of Sciences, 100(15), 8788-8792.

Kennedy, C. M., Lonsdorf, E., Neel, M. C., Williams, N. M., Ricketts, T. H., Winfree, R., ... \& Carvalheiro, L. G. (2013). A global quantitative synthesis of local and landscape effects on wild bee pollinators in agroecosystems. Ecology letters, 16(5), 584-599.

Larson, J. L., Kesheimer, A. J., \& Potter, D. A. (2014). Pollinator assemblages on dandelions and white clover in urban and suburban lawns. Journal of Insect Conservation, 18(5), 863-873.

Leong, M., Kremen, C., \& Roderick, G. K. (2014). Pollinator interactions with yellow starthistle (Centaurea solstitialis) across urban, agricultural, and natural landscapes. PloS ONE, 9(1), e86357.

Leong, M., Ponisio, L. C., Kremen, C., Thorp, R. W., \& Roderick, G. K. (2016). Temporal dynamics influenced by global change: bee community phenology in urban, agricultural, and natural landscapes. Global change biology, 22(3), 1046-1053.

Lonsdorf, E., Kremen, C., Ricketts, T., Winfree, R., Williams, N., \& Greenleaf S. (2009). Modelling pollination services across agricultural landscapes. Annals of Botany, 103:1589-1600.

Lowenstein, D. M., Matteson, K. C., Xiao, I., Silva, A. M., \& Minor, E. S. (2014). Humans, bees, and pollination services in the city: the case of Chicago, IL (USA). Biodiversity and conservation, 23(11), 2857-2874.

Lowenstein, D.M., K.C Matteson, E.S. Minor. (2015). Diversity of wild bees supports pollination services in an urbanized landscape. Oecologia, 179: 811-821.

Matteson, K. C., \& Langellotto, G. A. (2009). Bumble bee abundance in New York City community gardens: implications for urban agriculture. Cities and the Environment (CATE), $2(1), 5$.

Matteson, K. C., \& Langellotto, G. A. (2010). Determinates of inner city butterfly and bee species richness. Urban Ecosystems, 13(3), 333-347. 
Matteson, K. C., \& Langellotto, G. A. (2011). Small scale additions of native plants fail to increase beneficial insect richness in urban gardens. Insect Conservation and Diversity, 4(2), 8998.

Matteson, K. C., Grace, J. B., \& Minor, E. S. (2013). Direct and indirect effects of land use on floral resources and flower-visiting insects across an urban landscape. Oikos, 122(5), 682-694.

Milesi, C., Running, S. W., Elvidge, C. D., Dietz, J. B., Tuttle, B. T., \& Nemani, R. R. (2005). Mapping and modeling the biogeochemical cycling of turf grasses in the United States. Environmental Management, 36(3), 426-438.

Minor E., J.A. Belaire, A. Davis, M. Franco, \& M. Lin. (2016). Socioeconomics and neighbor mimicry drive urban yard and neighborhood vegetation patterns. In R. Francis (Ed.), Urban Landscape Ecology: Science, Policy and Practice. Abington: Routledge.

Pawelek, J., Frankie, G. W., Thorp, R. W., \& Przybylski, M. (2009). Modification of a community garden to attract native bee pollinators in urban San Luis Obispo, California. Cities and the Environment (CATE), 2(1), 7.

Pellissier, V., Muratet, A., Verfaillie, F., \& Machon, N. (2012). Pollination success of Lotus corniculatus (L.) in an urban context. Acta Oecologica, 39:94-100.

Potts, S. G., Vulliamy, B., Dafni, A., Ne'eman, G., \& Willmer, P. (2003). Linking bees and flowers: how do floral communities structure pollinator communities?. Ecology, 84(10), 26282642.

Potts, S. G., Vulliamy, B., Roberts, S., O'Toole, C., Dafni, A., Ne'eman, G., \& Willmer, P. (2005). Role of nesting resources in organising diverse bee communities in a Mediterranean landscape. Ecological Entomology, 30(1), 78-85.

Ricketts, T. H., Regetz, J., Steffan-Dewenter, I., Cunningham, S. A., Kremen, C., Bogdanski, A., ... \& Morandin, L. A. (2008). Landscape effects on crop pollination services: are there general patterns?. Ecology letters, 11(5), 499-515.

Robbins, P., \& Birkenholtz, T. (2003). Turfgrass revolution: measuring the expansion of the American lawn. Land Use Policy, 20(2), 181-194.

Robbins, P. (2012). Lawn people: How grasses, weeds, and chemicals make us who we are. Temple University Press.

Senapathi, D., Biesmeijer, J. C., Breeze, T. D., Kleijn, D., Potts, S. G., \& Carvalheiro, L. G. (2015). Pollinator conservation - the difference between managing for pollination services and preserving pollinator diversity. Current Opinion in Insect Science, 12, 93-101.

Sharp, R., Tallis, H.T., Ricketts, T., Guerry, A.D., Wood, S.A., Chaplin-Kramer, R., Nelson, E., Ennaanay, D., Wolny, S., Olwero, N., Vigerstol, K., Pennington, D., Mendoza, G., Aukema, J., Foster, J., Forrest, J., Cameron, D., Arkema, K., Lonsdorf, E., Kennedy, C., Verutes, G., Kim, C.K., Guannel, G., Papenfus, M., Toft, J., Marsik, M., Bernhardt, J., Griffin, R., Glowinski, K., 
Chaumont, N., Perelman, A., Lacayo, M. Mandle, L., Hamel, P., and Vogl, A.L. (2014). InVEST User's Guide. The Natural Capital Project, Stanford.

Smith, L. S., Broyles, M. E., Larzleer, H. K., \& Fellowes, M. D. (2015). Adding ecological value to the urban lawnscape. Insect abundance and diversity in grass-free lawns. Biodiversity and Conservation, 24(1), 47-62.

Taylor, J. R., \& Lovell, S. T. (2012). Mapping public and private spaces of urban agriculture in Chicago through the analysis of high-resolution aerial images in Google Earth. Landscape and Urban Planning, 108(1), 57-70.

Tornaghi, C. (2014). Critical geography of urban agriculture. Progress in Human Geography, 38(4), 551-567. 


\section{TABLE CAPTIONS}

Table 1. Land cover composition for the study area in square kilometers and as a percentage of the land within the city limits. The last three columns contain the expert estimates of nesting and floral resources for each land cover. The last column gives the estimates of floral resources under landscape modification scenarios. These values are needed to run InVEST's pollination model.

Table 2. Summary of floral enhancement scenarios for simulations. CGs stands for Community Gardens. 
TABLE 1

\begin{tabular}{cccccc}
\hline $\begin{array}{c}\text { Land cover } \\
\text { type }\end{array}$ & $\begin{array}{c}\text { Land } \\
\text { cover } \\
\left(\mathbf{k m}^{\mathbf{2}}\right)\end{array}$ & $\begin{array}{c}\text { Land cover } \\
(\boldsymbol{\%})\end{array}$ & $\begin{array}{c}\text { Nesting } \\
\text { availability }\end{array}$ & $\begin{array}{c}\text { Floral } \\
\text { abundance }\end{array}$ & $\begin{array}{c}\text { Floral } \\
\text { abundance } \\
\text { for scenarios }\end{array}$ \\
\hline Trees & 160.1 & 16.5 & 0.5 & 0.25 & 0.25 \\
Water & 130.5 & 13.4 & 0 & 0 & 0 \\
Impervious & 456.9 & 47.0 & 0 & 0 & 0 \\
Bare Soil & 45.8 & 4.7 & 0.25 & 0 & 0 \\
Grass & 178.1 & 18.3 & 0.5 & 0.3 & 0.9 \\
\hline
\end{tabular}


TABLE 2

\begin{tabular}{cc}
$\begin{array}{c}\text { Scenario } \\
\text { identifier }\end{array}$ & $\begin{array}{c}\text { Description } \\
\text { of scenario }\end{array}$ \\
\hline 1 & Change grass located only in parks to flower gardens \\
2 & Change grass located only within $250 \mathrm{~m}$ of CGs to flower gardens \\
$3 \mathrm{a}$ & Change grass located only within $500 \mathrm{~m}$ of CGs to flower gardens \\
$3 \mathrm{~b}$ & Change grass located only within $750 \mathrm{~m}$ of CGs to flower gardens \\
$3 \mathrm{c}$ & Change grass located only within $1 \mathrm{~km}$ of CGs to flower gardens \\
\hline
\end{tabular}




\section{FIGURE CAPTIONS}

Figure 1. Study area with inset of United States.

Figure 2. Map of pollination supply score and location of sites used for model validation, i.e. sites where bees were collected.

Figure 3. InVEST pollination module model validation (abundance and richness).

Figure 4. Effect of landscape modification scenarios on pollination supply scores. Each circle represents a farm (residential or urban farm) within the study area. The different scenarios are on the $\mathrm{X}$-axes. Y-axes represent change in pollination supply scores for each scenario compared to baseline. Note that each $y$-axis has a different maximum. The thick line for each box is the median change (increase) in pollinator supply score for that scenario.

Figure 5. Results of Tukey HSD test for the 5\% change in grassy landscapes for urban farms and community gardens (a), and residential gardens (b). If a confidence interval does not contain zero, the corresponding means are significantly different (these are also marked by a * in the figure). 


\section{Appendix Caption}

Table A1. List of genera, total number of individuals, and estimated foraging distances in meters for bees collected at the 14 validation sites across the City of Chicago, Illinois, USA. Foraging distances were estimated using measures of intertegular span and equations from Greenleaf et al. (2007). The last summary row of the table gives the total number of bees collected, and the mean estimated foraging distance (one per genus) in meters. This is not the mean estimated foraging distance weighed by number of individuals collected, which would be approximately 500 meters. 


\section{Appendix}

\begin{tabular}{lcc} 
Genera & $\begin{array}{c}\text { Number of } \\
\text { individuals collected }\end{array}$ & $\begin{array}{c}\text { Estimated Foraging Distance } \\
(\mathbf{m})\end{array}$ \\
\hline \hline Agapostemon & 96 & 614 \\
Andrena & 3 & 293 \\
Anthidium & 6 & 898 \\
Apis & 14 & 2000 \\
Augochlora & 1 & 126 \\
Bombus & 9 & 1955 \\
Ceratina & 3 & 61 \\
Colletes & 1 & 915 \\
Halictus & 78 & 321 \\
Hoplitis & 1 & 259 \\
Hylaeus & 4 & 64 \\
Lasioglossum & 146 & 88 \\
Megachile & 14 & 1208 \\
Melissodes & 57 & 854 \\
Summary & 433 & 690 \\
\hline
\end{tabular}

367 


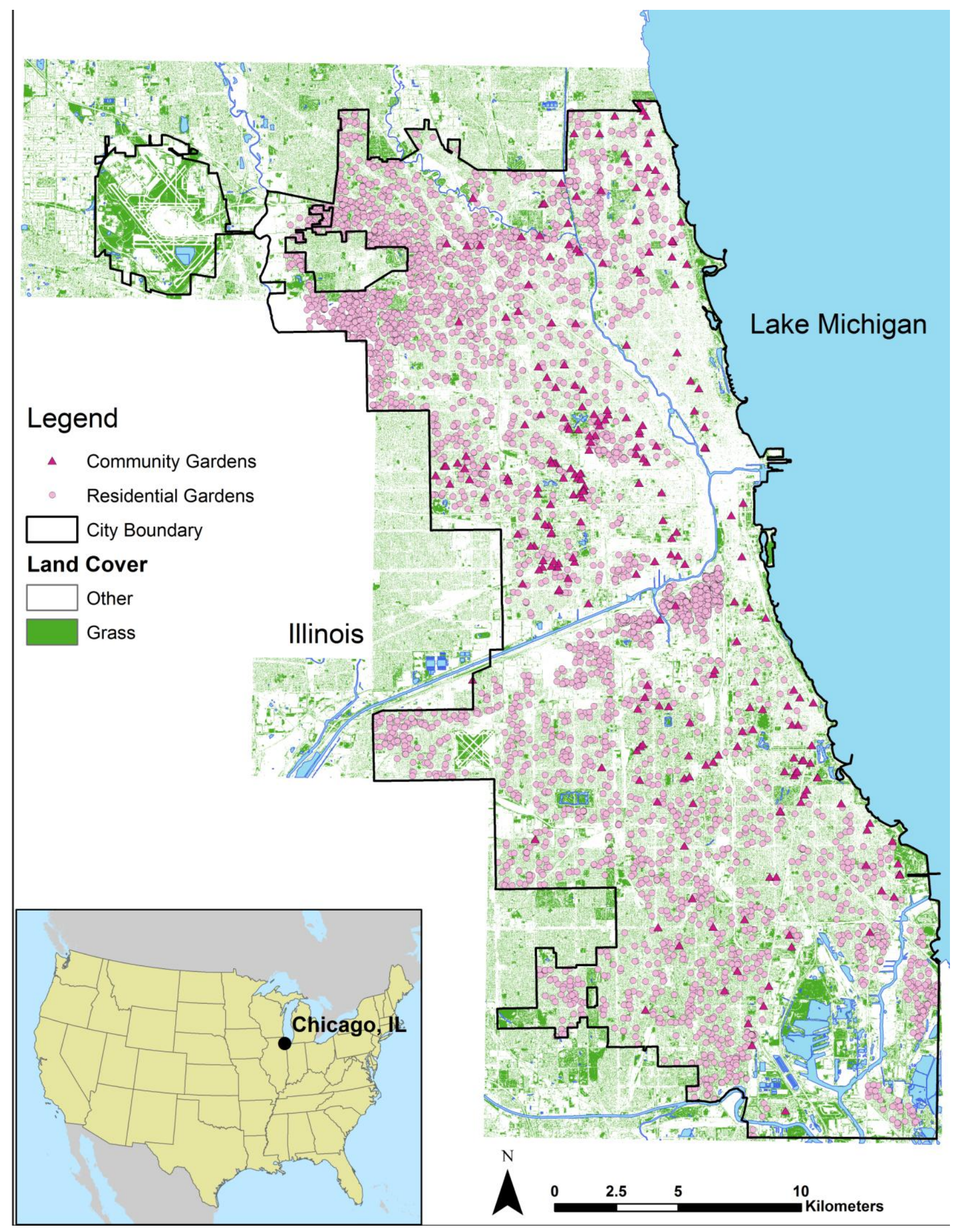




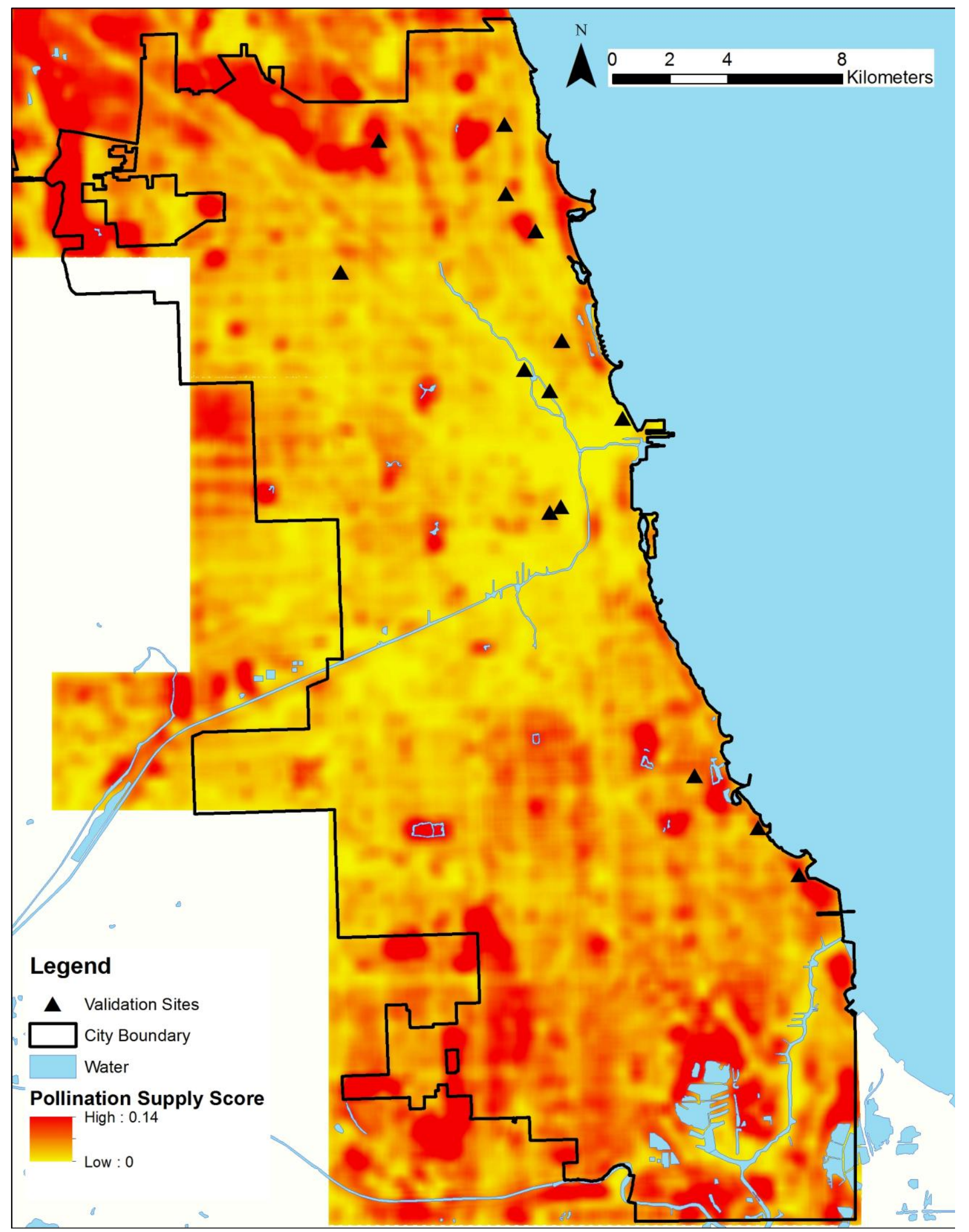



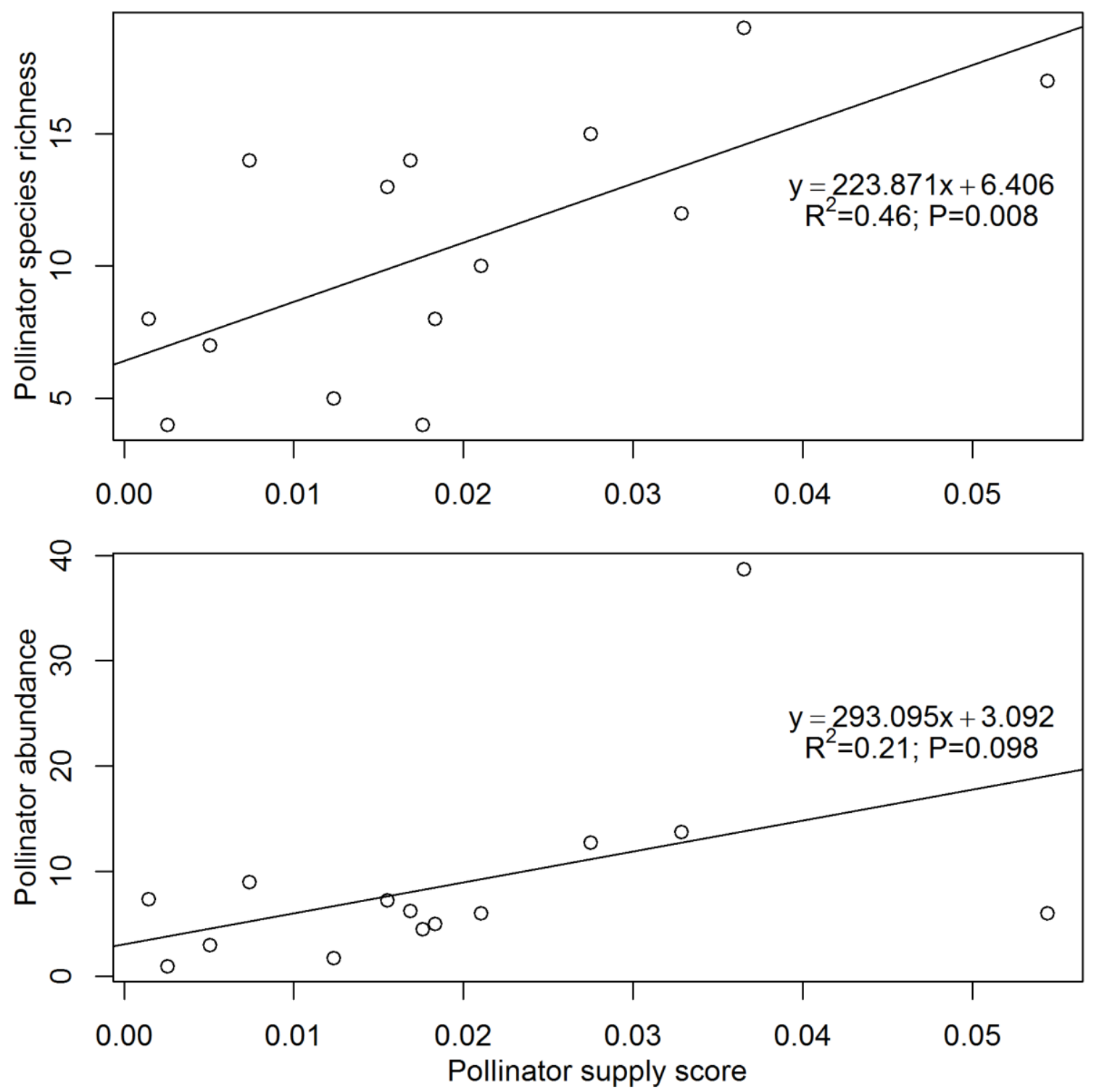

370 
4a) Urban Farms

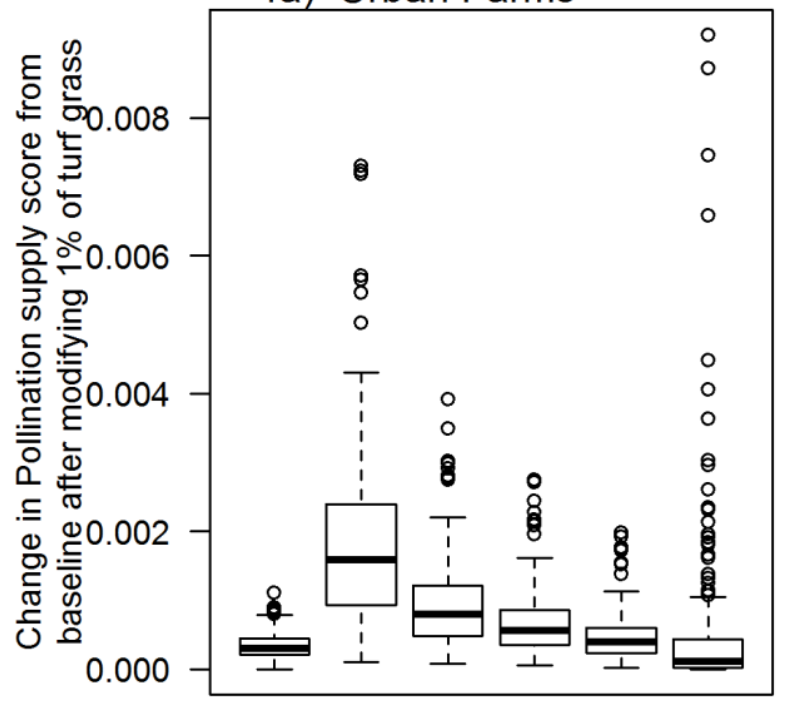

4c) Urban Farms

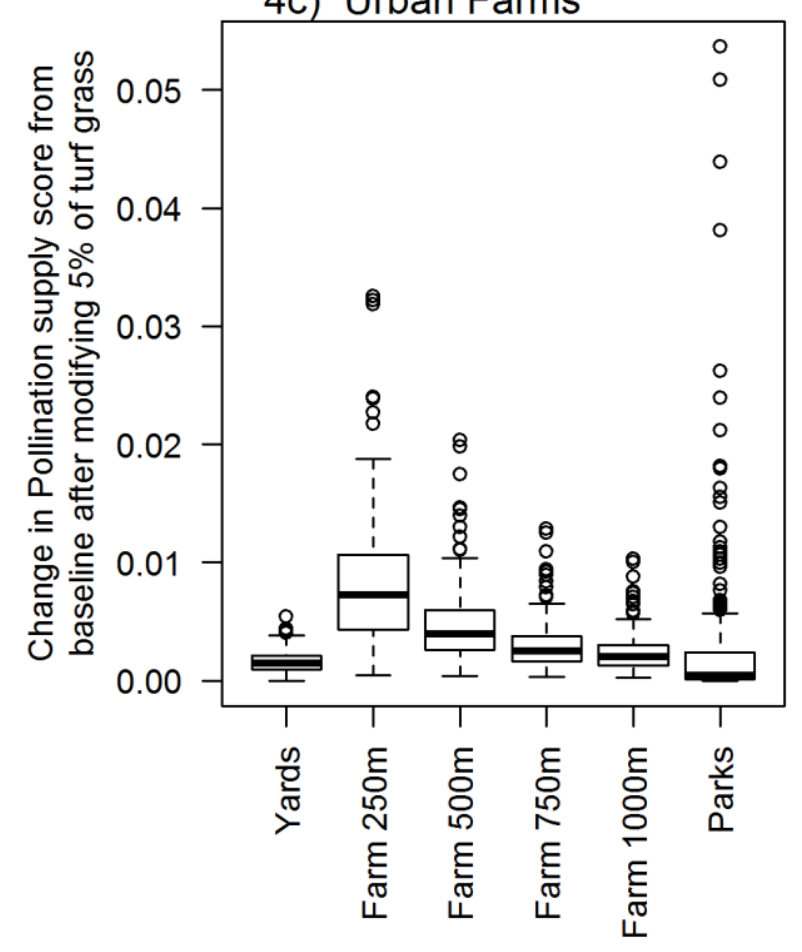

4b) Residential gardens

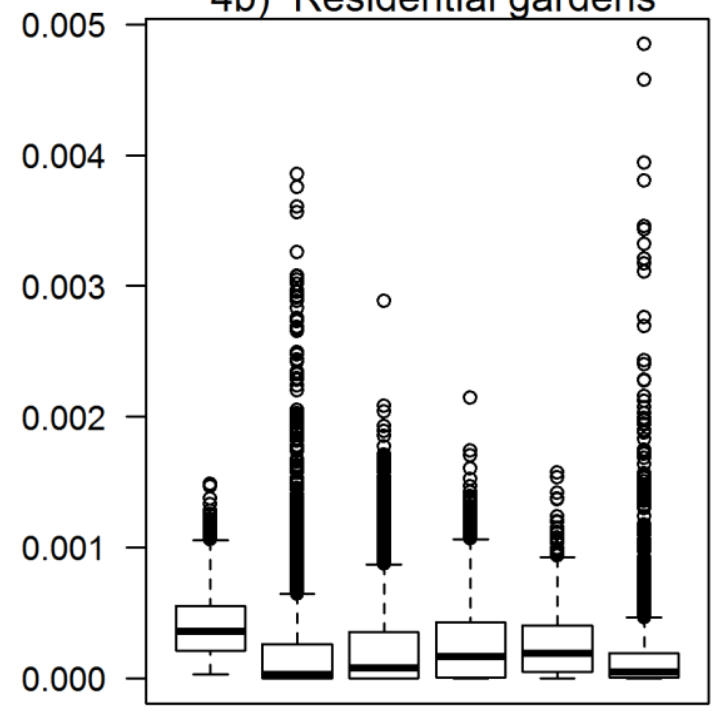

4d) Residential gardens

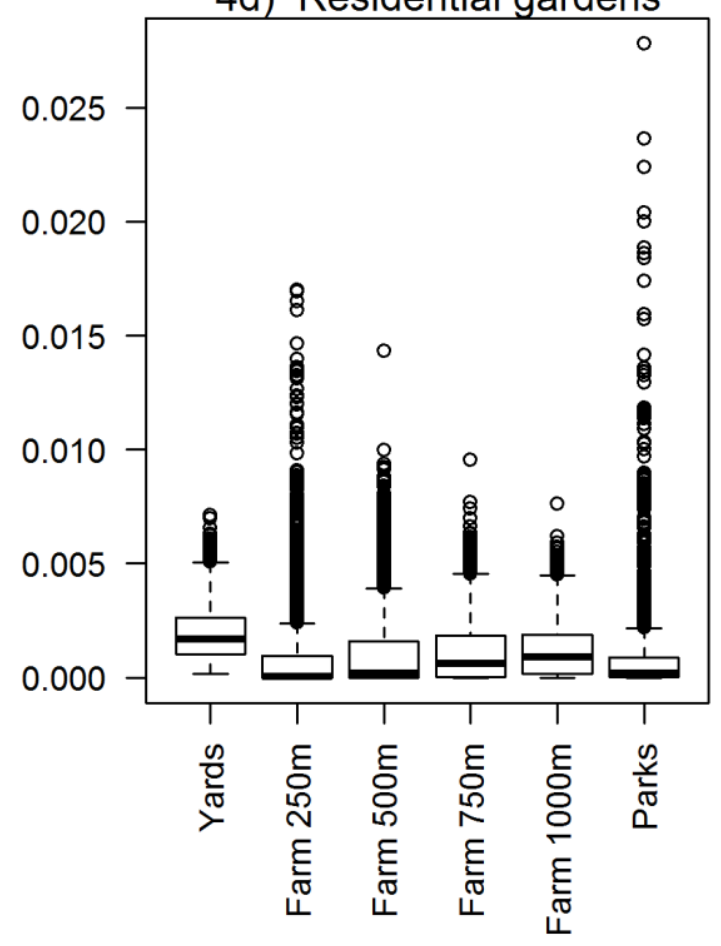


$\mathbf{9 5} \%$ family-wise confidence level

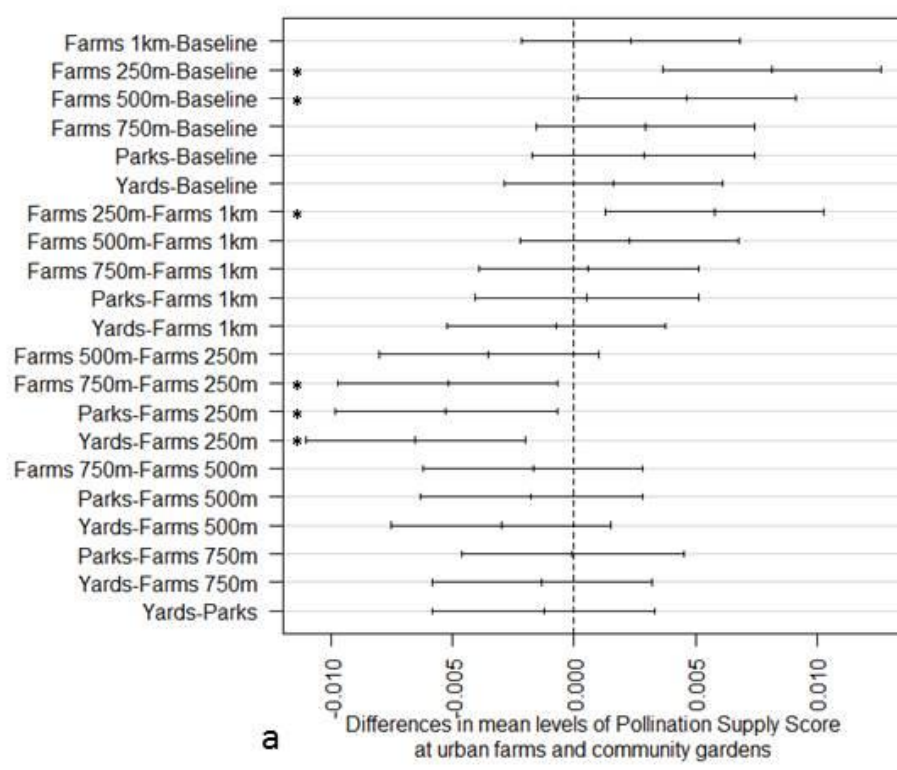

$\mathbf{9 5} \%$ family-wise confidence level

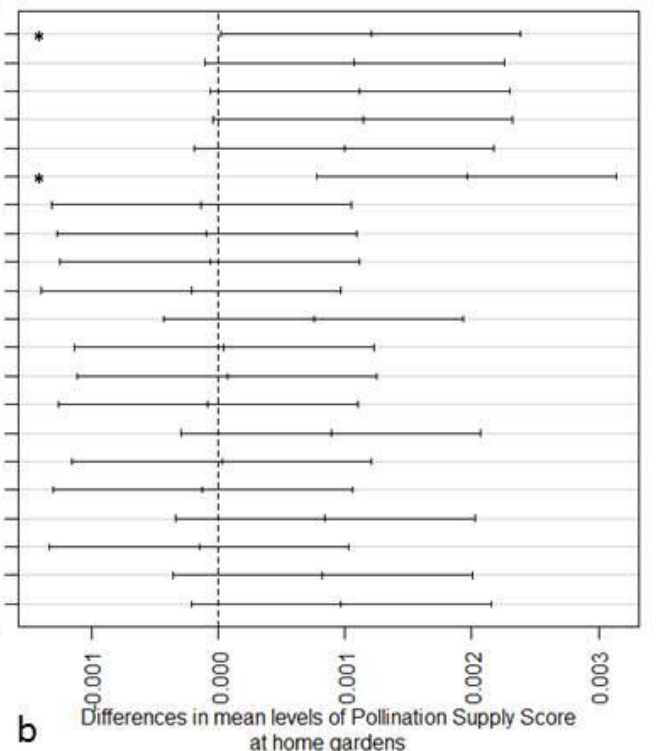




\section{ACKNOWLEDGEMENTS}

374 This research was supported by the National Science Foundation and the U.S. Forest Service

375 under the ULTRA-Ex program (grant number 0948484). The authors wish to thank the City of

376 Chicago for providing them with the land cover dataset, Brandon Flessner for developing Figure

3771 and running some of the scenarios, and two anonymous reviewers for their constructive

378 feedback.

379 